\title{
A SINGULAR CASE
}

or

\section{EXPULSION}

or 1

\section{BLIGHTED FOETUS AND PLACENTA}

AT SEVEN MONTHS,

A LIVING CHILD STILL REMAINING TO THE FULL PERIOD

or

\section{UTERO-GESTATION.}

By. JOHN CHAPMAN, Esq.

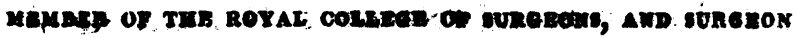

Is wumbor.

COMMUNICATED

BY Dr. BAILLIE.

\section{Read March 3, 1818.}

Although the following case may not contain any useful practical hints, or be capable of any deduction that may improve or increase our present knowledge, yet from its novelty and singularity will perhaps be considered not entirely unworthy the notice of the Society. Hitherto I have not been able to meet with any thing like it on record: the only case that I know bearing any 
analogy, is that published by the late Dr. Clarke in the 16th Volume of the Medical and Physical Journal, page 53. but they will be seen to differ in their circumstances, as in the latter a blighted foetus (about the third month) was expelled two days after the birth of a living child; whereas in that I am about to relate, a similar instance took place two months before.

On the 9th of October, 1816, Mr. R. of Clewer called on me to say that his wife, being about seven months advanced in pregnancy, was taken very unwell, and he expected might require my assistance in the course of the day; adding, that about three o'clock in the morning, (it was now nearly nine o'clock,) she had been suddenly surprised with a considerable flooding, and notwithstanding it was much abated, she appeared getting into pain. I informed him, it would be better for me to see her immediately; that the hæmorrhage might again increase and yet labour not come on at present, and it was necessary to give her some directions for her management.

On my arrival, the nurse informed me the pains had continued to increase, and that something had just come away which she had preserved in a basin. On examining this substance, I discovered it to be a perfectly healthy placenta, the size they usually are between five and six months, to which was attached

0.2 
the membranes also, quite pierfect, but of a dirty fellow colour, flattened and closely embracing a small foetus not larger than they are generally seen between three and four months, without any liquer amnii, although it did not eppear that any could have escaped. After these had passed, the pains and flooding entirely ceased, but my patient ob. served, "I am not any less; and I still. feel the child as much as ever." I instantly applied my hand to the abdonen and found she was quite correct, for that she was certainly as large as wo. men generally are at seven months; and after keeping it there a few minutes, I very sensibly perceived the motion of the child.

Iremained with her for some time without either pain or hæmorrhage returning; I did not thenefore think it necessary to make a more particular examination, but enjoined quiet, ordered an opiate to allay the constitutional disturbance occasioned by the alarm, and directed that I might be instantly sent for, should either hæmorrhage or pain return, and then took my leave with the placenta and foetus which $I$ have preserved in spirits.

I continued to visit my patient daily for about a week, and afterwards occasionally for two or three weeks more; and as she remained free from pain, and had continued progressively to recover her strength, I allowed ber to join her family as 
ustal, observing she would now most probably go on very well to the end of her pregnanoy. From this time I did not either see or hear from her till the 10th of December, when $I$. was sent for in haste. She was now in violent pain, and the head of the child had just passed the os externum as I entered the room : two or three more pains completed the delivery of a very fine full-grown little girl : the placenta soon followed. She had a very good getting up, without an irregular or ill symptom.

I have mentioned the case, and shewn the placenta and fotus to several of my medical friends, who all think it a very uncommon and singular case ; so that I am quite rejoiced to have an oppor. tunity of presenting the placenta and foetus to the Society; and that the little girl also continues a living witness.

I have thus far given a correct statement of this as far as I know unparalleled case, and do not attempt to offer any remarks more than to observe, that I certainly did not expect the os uteri could have been dilated to the size it must have been, accompanied with the necessary expulsive pains, to force this placenta and foetus through it, and yet the pains again subside without going on to empty the uterus; and not only going entirely off but that gestation should con- 
tinue to go on equally well as if the uterus had not suffered any disturbance, but had just thrown off what it was unequal to bring to perfection, and all was well again. Mrs. R. had not menstruated since the beginning of March. 